\title{
A Proposed Development of Dc-Dc Transformer Using ĆUK Regulator
}

\author{
Md.Rakibul Hasan, Mohammad Ashraf Hossain Sadi, Ifat Al-Baqee, Md. Shahidul Islam Bhuiyan and \\ Md. Kamal Hossain
}

\begin{abstract}
In many industrial applications, it is required to convert a fixed-voltage dc source into a variable -voltage dc source. DC-DC converters can convert DC voltage from one level to another level without using the $\mathrm{AC}$ transformer. This paper describes a new strategy for converting the DC voltage to step-up and step-down efficiently and effectively. It can be accomplished using Buck, Boost, Buck Boost and Ćuk converter. Amongst which Buck converter can only step down the DC voltage and Boost converter can only step up the DC voltage. But the Buck Boost and Ćuk converter can step up or step down the voltage. For ripple in the output current and requirement of filter, Buck Boost converter has been intentionally avoided. Also, experience shows that Buck Boost is an unreliable converter which may malfunction at any time during operation. And hence, Ćuk converter is chosen for the conversion of the DC voltage. Though the Cuk converter has an inverted output but with suitable connection and also a converter with zero ripples, it can be used successfully.
\end{abstract}

Index Terms-Duty Cycle, Ćuk converter, DC transformer.

\section{INTRODUCTION TO DC-DC CONVERTER}

A DC-to-DC converter is a device that accepts a DC input voltage and produces a DC output voltage. Typically the output produced is at a different voltage level than the input. In addition, DC-to-DC converters are used to provide noise isolation, power bus regulation, etc. In electronic engineering, a DC to DC converter is a circuit which converts a source of direct current (DC) from one voltage level to another [3]. It is a class of power converter. The purpose of a DC-DC converter is to supply a regulated DC output voltage to a variable-load resistance from a fluctuating DC input voltage [1]. In many cases the DC input voltage is obtained by rectifying a line voltage that is changing in magnitude. DC-DC converters are commonly used in applications requiring regulated DC power, such as computers, medical instrumentation, communication devices, television receivers, and battery chargers. DC-DC converters are also used to provide a regulated variable $\mathrm{DC}$ voltage for $\mathrm{DC}$ motor speed control applications [1]. The output voltage in DC-DC converters is generally controlled using a switching concept. Early DC-DC converters were known as choppers with silicon-controlled rectifiers (SCRs) used as the switching mechanisms. Modern DC-DC converters classified as switch mode power supplies (SMPS) employ insulated gate bipolar transistors (IGBTs) and metal oxide silicon field effect

Manuscript received March 31, 2011.

Mohammad Ashraf Hossain Sadi, Lecturer, Dept of EEE. Stamford University Bangladesh. transistors (MOSFETs). The regulation of the average output voltage in a DC-DC converter is a function of the on-time. Pulse width modulation (PWM) is the most widely used method of controlling the output voltage [9]. The device that converts directly from DC to DC is known as DC-DC converter. DC chopper is a well known DC-DC converter. It is required to convert a fixed voltage DC source into another level or a variable voltage dc source in many industrial applications. A DC-DC converter can be considered as DC equivalent of an $\mathrm{AC}$ transformer with a continuously variable turn ratio. It can be used to step-down \& step-up a DC voltage source.

\section{DC TRANSFORMER}

A DC transformer converts DC voltage by employing multiple charging circuits formed by connecting charging semiconductor elements, such as diodes and thyristors, in series to opposite ends of a condenser, and DC low voltage is applied to opposite input terminals of all the charging circuits connected in parallel to each other. The condensers of all the charging circuits are connected in series with each other between a pair of output load terminals. Gating circuit means are operable to trigger conductive both semi-conductor devices of each charging circuit to charge the associated condenser to the voltage of a low voltage source and, with all condensers charged to the voltage of the source, to impress the sum of the voltages of all condensers between the output load terminals. In the first embodiment of the invention, the charging circuits are gated conductive in succession. In a second embodiment of the invention, respective semi-conductor devices, each having a gating electrode, are connected in series between each pair of condensers. The charging circuits are gated conductive simultaneously in alternation with the gating conductive of all of the semi-conductor devices connected in series between pairs of condensers. In a third embodiment of the invention, the charging circuits are arranged to form sets of basic voltage transformation circuits and the application of gating current to the discharging semi-conductor elements is delayed by a slight amount. A DC transformer comprising, in combination, a plurality of charging circuits each having a pair of opposite terminals, each circuit including, between its opposite terminals, a condenser connected in series between a pair of charging semi-conductor devices each having a gating electrode; circuit means connecting corresponding terminals of all said charging circuits in parallel with each other to a pair of first terminals of said transformer; means connecting all said condensers in series with each other between a pair of second terminals of said transformer; and gating circuit 
means operable to trigger conductive both semi-conductor devices of each charging circuit simultaneously to charge the associated condensers to equal potentials responsive to connection of a low voltage DC source to said first terminals to impress the sum of the voltages of all said condensers between said second terminals and, responsive to connection of a high voltage DC source to said second terminals, to impress the common potential of all said condensers between said first terminals.

Many years ago, Dr. Ćuk invented the Integrated Magnetics concept, demonstrating that input inductor, isolation transformer and output inductor can be placed on a common magnetic core if they have identical AC voltage waveforms for any operating duty ratio. In the TESLA converter, the $\mathrm{AC}$ voltages of the input inductor and isolation transformer are always identical but the AC voltage on the output inductor becomes lower when duty ratio is less than 1 . Nevertheless, the New Integrated Magnetics structure, called DC Transformer (since DC flux and air-gap are eliminated) was created.

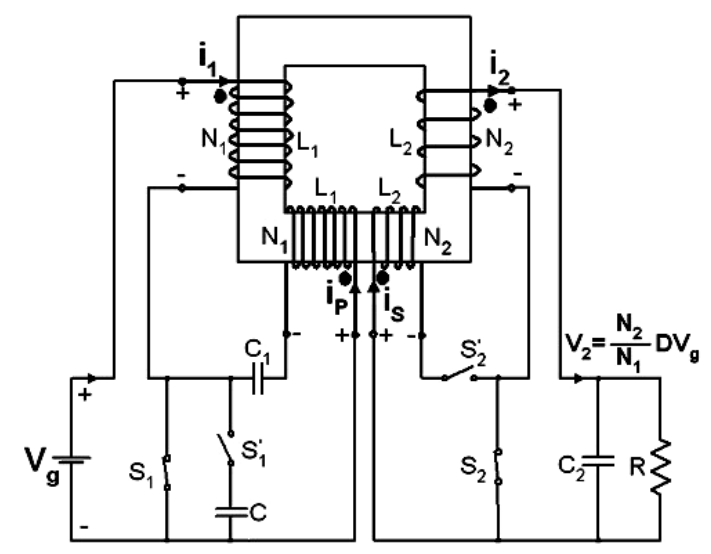

Fig 1. Commercially available DC Transformer

The DC-flux in the new Integrated Magnetics structure is nearly eliminated or significantly reduced for any operating condition! The sum of the DC-fluxes created by the currents in the windings of the input inductor $\mathrm{L}_{1}$ and transformer $\mathrm{T}$ is equal to the DC flux created by the current in the output inductor $\mathrm{L}_{2}$ winding. Hence, the new Integrated Magnetic is designed in such a way that the above identical DC-fluxes are opposing each other and thus result in a mutual cancellation of the DC-flux. This enables the elimination or significant reduction of the air gap, while the zero ripple feature on both the input and output inductors at the nominal operating point is still preserved.

\section{DC- DC CONVERTER OPERATION}

There are two basic types of DC-DC Converters operation. These are

i) Step-up operation

ii) Step-down Operation

\section{A. Step Down Operation}

A step-down dc chopper with a resistive load is shown in figure- given below. It is a series connection of DC voltage source Vs, controllable switch SW and a load resistance R. In most case, the switch SW has unidirectional voltage-blocking capabilities and unidirectional current-conduction capabilities. The switch is implemented with power MOSFET, BJT or IGBT. The switch is being operated with a duty ratio $\mathrm{D}$ defined as the ratio of the switch on time to the sum of the on time and off times. For a constant frequency operation

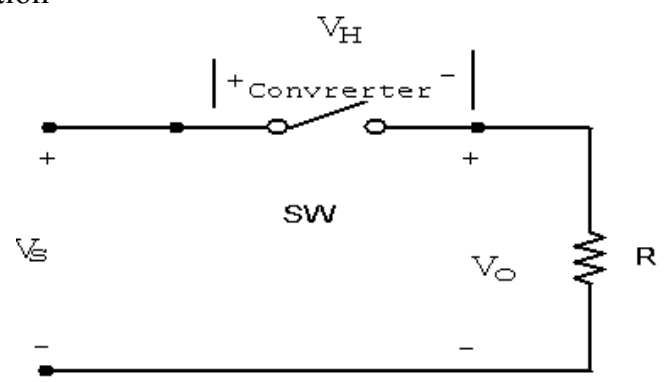

Fig 2 : Step Down Converter Transformer

Mathematical analysis

$$
D=\frac{t_{\text {on }}}{\left(t_{\text {on }}+t_{\text {eff }}\right)}
$$

$D=\frac{t_{Q M}}{T} \quad$ Where $T$ is the time period.

The average output voltage is given by

$$
\begin{aligned}
V_{\mathrm{a}} & =\frac{1}{\mathrm{~T}} \int V_{\mathrm{Q}} \mathrm{dt} \\
& =\left(\frac{t_{1}}{\mathrm{~T}}\right) V_{\mathrm{g}} \mathrm{A}=\mathrm{DVS}
\end{aligned}
$$

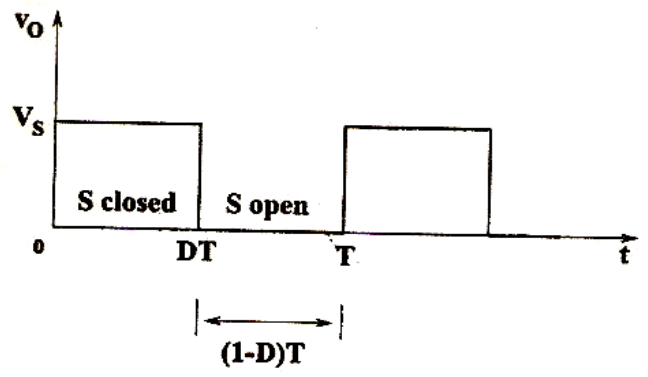

Fig 3. Waveform of Step Down Converter

and the average current, $\quad I_{a}=\frac{V_{\mathrm{g}}}{R}=\frac{D V_{s}}{R}$

\section{B. Step Up Operation}

Step-up converter consists of DC input voltage Vs, Inductor L, Control switch, Diode $\mathrm{D}_{1}$, Filter capacitor $\mathrm{C}_{\mathrm{L}}$, \& Load resistance $R_{L}$

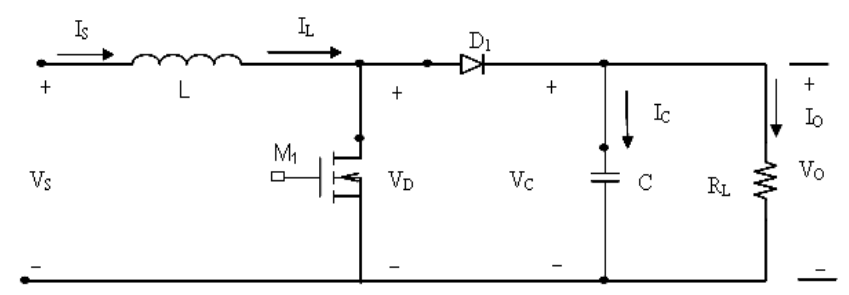

Fig 4. Step Up Converter

When the switch is on state, the current in the inductor increases linearly \& the diode D 1 is off at that time. When the switch is turned off, the energy stored in the inductor is released through D1 to the $\mathrm{O} / \mathrm{P} \mathrm{RC}$ circuit. 


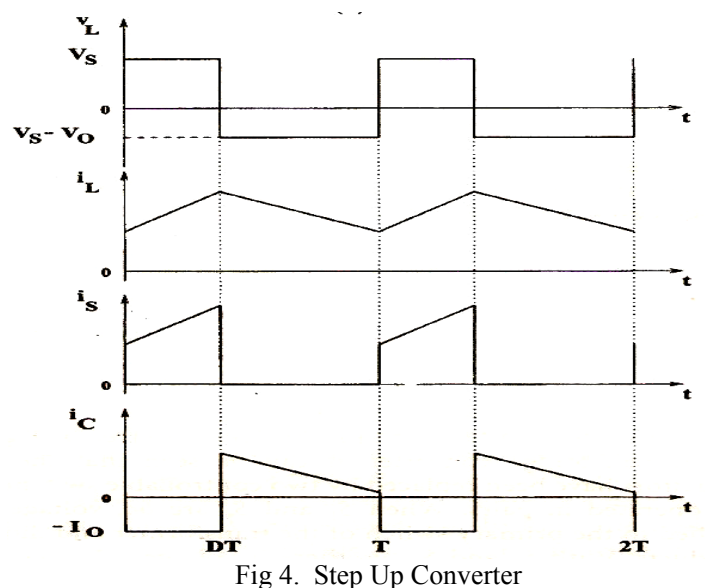

Mathematical analysis

The average output voltage

$V_{a}=V_{s}+L \frac{d i}{d t}=V_{s}+L \frac{\Delta l}{t_{z}}[$ Here $\Delta \mathrm{I}$ is the

inductor current]

$$
\begin{aligned}
& =V_{s}+V_{s} \frac{t_{1}}{t_{2}} \\
& =V_{s}\left(1+\frac{t_{1}}{t_{2}}\right) \\
& =V_{s}\left(\frac{1}{1-D}\right)
\end{aligned}
$$

\section{BASIC SWITCHING OF DC-DC CONVERTERS}

DC converters can be used as switching mode regulators to convert a dc voltage, normally unregulated, to a regulated dc output voltage. The regulation is normally achieved by PWM (Pulse Width Modulation) at fixed frequency and the switching device is normally BJT, MOSFET or IGBT.

Switching regulators are commercially available as integrated circuits. The designer can select the switching frequency by choosing the value of $\mathrm{R}$ and $\mathrm{C}$ of the frequency oscillators.

Basic converters are of four types:
a. Buck Regulators
b. Boost Regulators
c. Buck-boost Regulators
d. Ćuk Regulators

A. Ćuk Regulators

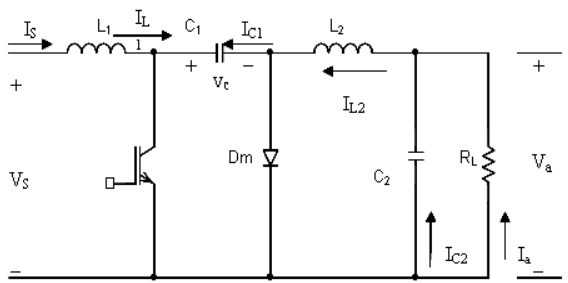

Fig 5. Ćuk Regulator

The circuit arrangement of the Cŭk regulator using a power bipolar junction transistor is shown in figure below. Similar to the buck-boost regulator, the Cŭk regulator provides an output voltage that is less than or greater than the input voltage, but the output voltage is opposite to that of the input voltage. It is named after its inventor. When the input voltage is turned on and transistor $\mathrm{Q}_{1}$ is switched off, diode Dm is forward biased and capacitor $C_{1}$ is charged though $L_{1}$, $\mathrm{D}_{\mathrm{m}}$, and the input supply $\mathrm{V}_{\mathrm{S}}$.

The circuit operation can be divided into two modes. Mode 1 begins when transistor $\mathrm{Q}_{1}$ is turned on at $\mathrm{t}=0$. The current though inductor $\mathrm{L}_{1}$ rises. At the same time the voltage of capacitor $\mathrm{C}_{1}$ reverse biases diode $\mathrm{D}_{\mathrm{m}}$ and turns it off. The capacitor $\mathrm{C}_{1}$ discharges its energy to the circuit formed by $\mathrm{C}_{1}$, $\mathrm{C}_{2}$, the load, and $\mathrm{L}_{2}$. The circuit arrangement of mode loperation is shown in figure below.

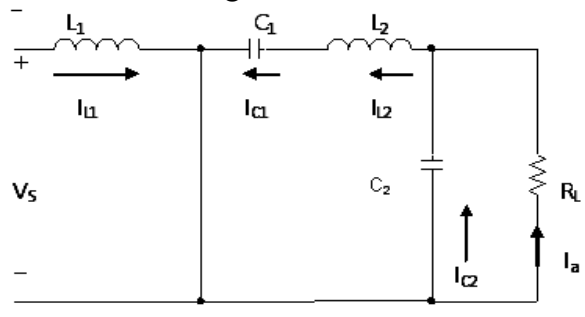

Fig 6. Mode 1 operation Ćuk Regulator

Mode 2 begins when transistor $\mathrm{Q}_{1}$ is turned of at $\mathrm{t}=\mathrm{t}_{1}$. The capacitor $\mathrm{C}_{1}$ is charged from the input supply and the energy stored in the inductor $\mathrm{L}_{2}$ is transferred to the load. The diode $\mathrm{D}_{\mathrm{m}}$ and transistor $\mathrm{Q}_{1}$ provide a synchronous switching action. The capacitor $\mathrm{C}_{1}$ is the medium for transferring energy from the source to the load. The circuit arrangement of mode 2 operation is shown in figure below.

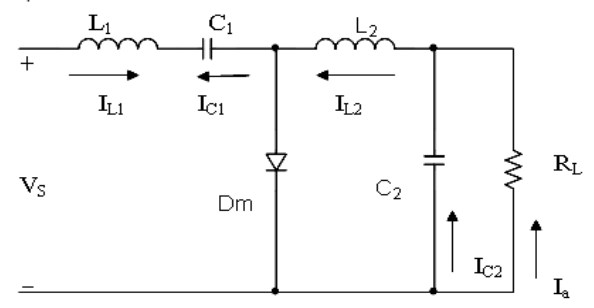

Fig 7. Mode 2 operation Ćuk Regulator

The waveforms for steady-state voltage and current of the Cŭk regulator are shown in figure below.

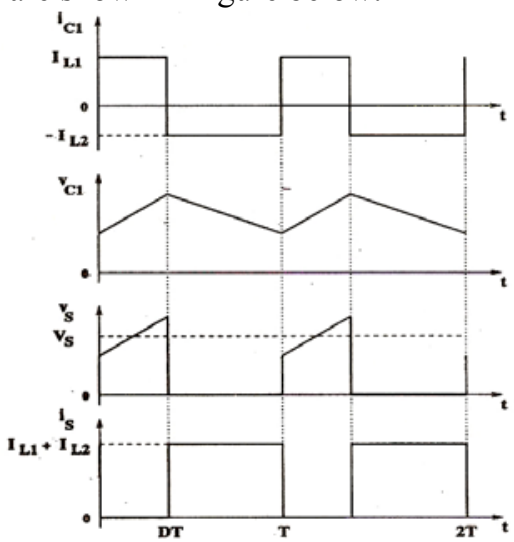

Fig 8. Waveform of the Ćuk Regulator

\section{Mathematical analysis}

Assuming that the inductor $\mathrm{L}_{1}$ current rises linearly from $\mathrm{I}_{\mathrm{L} 11}$ to $\mathrm{I}_{\mathrm{L} 22}$ in time $\mathrm{t}_{1}$,

$$
\begin{gathered}
V_{S}=L_{1} \frac{\left(I_{L 11}-I_{L 22}\right)}{t_{1}}=L_{1} \frac{\Delta I_{1}}{t_{1}} \\
\text { or } \Delta I_{1}=\frac{V_{S} t_{1}}{L_{1}}
\end{gathered}
$$


and due to the charged capacitor $\mathrm{C}_{1}$, the current of inductor $\mathrm{L}_{1}$ falls linearly from $\mathrm{I}_{\mathrm{L} 12}$ to $\mathrm{I}_{\mathrm{L} 11}$ in time $\mathrm{t}_{2}$,

$$
\begin{gathered}
V_{s}-V_{c 1}=-L_{1} * \frac{\Delta I_{1}}{t_{2}} \\
\text { or } \Delta I_{1}=-\frac{\left(V_{s}-V_{c 1}\right) t_{2}}{L_{1}}
\end{gathered}
$$

where $\mathrm{V}_{\mathrm{cl}}$ is the average voltage of capacitor $\mathrm{C}_{1}$, and $\Delta \mathrm{I}_{1}=\mathrm{I}_{\mathrm{L} 12}-\mathrm{I}_{\mathrm{L} 11}$. From above two equations we get,

$$
\Delta I_{1}=\frac{V_{S} t_{1}}{L_{1}}=-\frac{\left(V_{s}-V_{c 1}\right) t_{2}}{L_{1}}
$$

Substituting $\mathrm{t}_{1}=\mathrm{kT}$ and $\mathrm{t}_{2}=(1-\mathrm{k}) \mathrm{T}$ yields the average voltage of capacitor $\mathrm{C}_{1}$ is

$$
V_{c 1}=\frac{V_{s}}{1-k}
$$

Assuming that the inductor $\mathrm{L}_{2}$ current rises linearly from $\mathrm{I}_{\mathrm{L} 11}$ to $\mathrm{I}_{\mathrm{L} 22}$ in time $\mathrm{t}_{1}$,

$$
\begin{gathered}
V_{c 1}+V_{a}=L_{2} \frac{I_{L 22}-I_{L 21}}{t_{1}}=L_{2} \frac{\Delta I_{2}}{t_{1}} \\
\operatorname{or} \Delta I_{2}=\frac{\left(V_{G 1}+V_{a}\right) t_{1}}{L_{2}}
\end{gathered}
$$

and the current of inductor $\mathrm{L}_{1}$ falls linearly from $\mathrm{I}_{\mathrm{L} 22}$ to $\mathrm{I}_{\mathrm{L} 21}$ in time $\mathrm{t}_{2}$,

$$
\begin{gathered}
V_{u}=-L_{2} \frac{\Delta I_{2}}{t_{2}} \\
\operatorname{or} \Delta I_{2}=-\frac{V_{s} t_{2}}{L_{2}}
\end{gathered}
$$

Where $\Delta \mathrm{I}_{2}=\mathrm{I}_{\mathrm{L} 22}-\mathrm{I}_{\mathrm{L} 21}$. From the above two equation we get,

$$
\Delta I_{\mathrm{z}}-\frac{\left(V_{c 1}+V_{a}\right) t_{1}}{L_{2}}--\frac{V_{a} t_{2}}{L_{2}}
$$

Substituting $\mathrm{t}_{1}=\mathrm{kT}$ and $\mathrm{t}_{2}=(1-\mathrm{k}) \mathrm{T}$ yields the average voltage of capacitor $\mathrm{C}_{1}$ is,

$$
V_{c 1}=-\frac{V_{a}}{k}
$$

Equating $\mathrm{V}_{\mathrm{c} 1}$ from the above two equation, we can find the average output voltage as

$$
V_{a}=-\frac{V_{s} k}{1-k}
$$

Assuming a lossless circuit, $\mathrm{V}_{\mathrm{S}} \mathrm{I}_{\mathrm{S}}=\mathrm{V}_{\mathrm{a}} \mathrm{I}_{\mathrm{a}}=\mathrm{V}_{\mathrm{S}} \mathrm{I}_{\mathrm{a}} \mathrm{k} /(1-\mathrm{k})$ and the average input current is

$$
I_{s}=\frac{k I_{a}}{1-k}
$$

The Cŭk regulator is based on the capacitor energy transfer. As a result, the input current is continuous. The circuit has low switching losses and has high efficiency. When transistor $\mathrm{Q}_{1}$ is turned on, it has to carry currents of inductors $\mathrm{L}_{1}$ and $\mathrm{L}_{2}$. As a result a high peak current flows through transistor $Q_{1}$. Because the capacitor provides the energy transfer, the ripple current of the capacitor $\mathrm{C}_{1}$ is also high. This circuit also requires an additional capacitor and inductor.

\section{DC- DC CONVERTER USING CǓK CONVERTER}

From the designed circuit (Fig: 9) it is evident that the circuit can be controlled that means the output voltage can be controlled using the duty cycle variation. The choice of IGBT control parameter is a vital consideration for the voltage transformation. As seen in the previous section that for a Ćuk converter,
$\mathrm{M}(\mathrm{D})=\mathrm{D} /(1-\mathrm{D})$.

The basic parameters of the Ćuk converter $\mathrm{L}_{1}, \mathrm{C}_{1}, \mathrm{~L}_{2}, \mathrm{C}_{2}$ are also chosen to obtain the output 410 volt at maximum efficiency of the circuit.

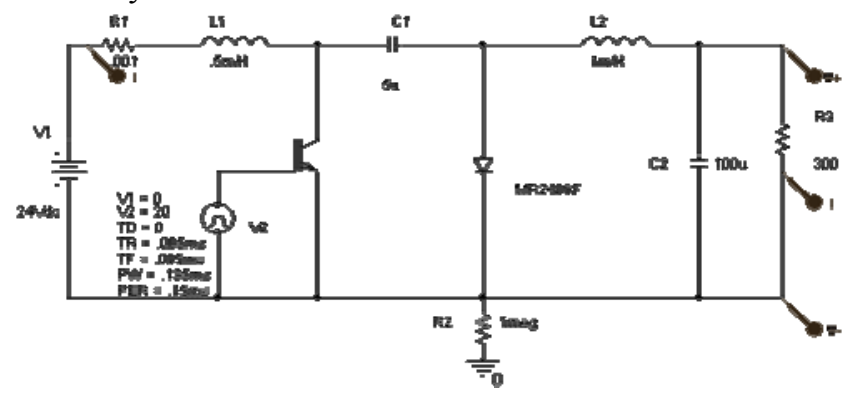

Fig 9. Operation of Ćuk converter (Ideal case)

The design circuit is tested by simulation method. The simulation results are as follows:

TABLE I. CASE 1: SHOWS THAT THE MAXIMUM VOLTAGE OCCURS AT $\mathrm{D}=0.95$

\begin{tabular}{|c|c|c|c|c|c|}
\hline $\mathrm{D}$ & $\mathrm{I}_{\text {in }}$ & $\mathrm{V}_{0}$ & $\mathrm{I}_{0}$ & $\mathrm{~V}_{0} / \mathrm{V}_{\text {in }}$ & $\mathrm{V}_{0} \mathrm{I}_{0} / \mathrm{V}_{\text {in }} \mathrm{I}_{\text {in }}(\%)$ \\
\hline 0.1 & 1.07 & 30.84 & 0.102 & 1.28 & 12.2 \\
\hline 0.2 & 1.76 & 50.82 & 0.169 & 2.11 & 20.3 \\
\hline 0.3 & 2.42 & 70.28 & 0.234 & 2.92 & 28.3 \\
\hline 0.4 & 3.24 & 89.98 & 0.299 & 3.74 & 34.5 \\
\hline 0.5 & 4.01 & 112.61 & 0.375 & 4.69 & 43.8 \\
\hline 0.6 & 4.76 & 129.30 & 0.429 & 5.38 & 48.5 \\
\hline 0.7 & 5.58 & 149.01 & 0.496 & 6.20 & 55.1 \\
\hline 0.8 & 6.87 & 164.57 & 0.548 & 6.85 & 54.6 \\
\hline 0.9 & 25.72 & 409.40 & 1.36 & 17.05 & 90.1 \\
\hline 0.95 & 496.86 & 740.43 & 2.46 & 30.85 & 15.2 \\
\hline 0.99 & 575.86 & 163.42 & 0.544 & 6.80 & 0.64 \\
\hline
\end{tabular}

Case 2 Shows the duty cycle and voltage transfer function

Case 3: Duty cycle Vs Efficiency. It is evident that the maximum efficiency occurs at $\mathrm{D}=0.9$

These entire curves show the efficiency and effectiveness of the designed circuit. Observation shows that circuit is efficient and operates at $90 \%$ efficiency.

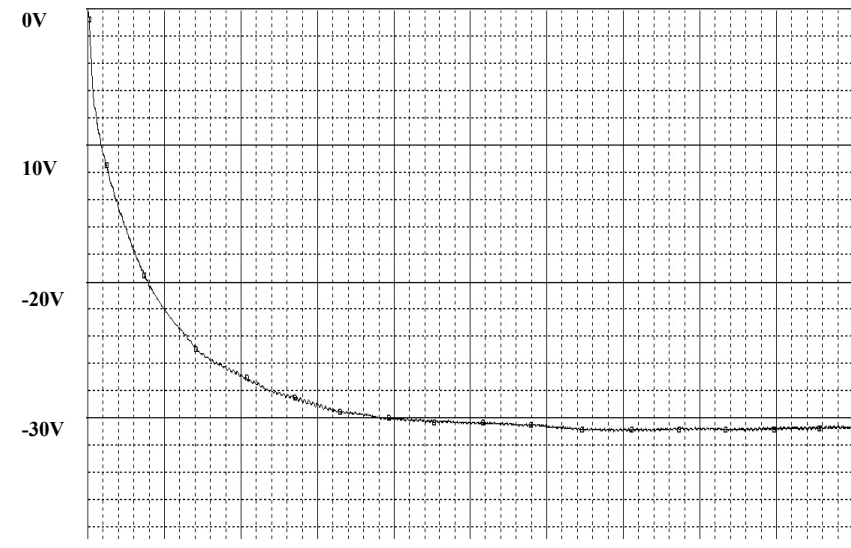

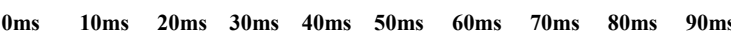
V (L2:2,V1:-)

Fig 10. Duty cycle Vs output voltage when $\mathrm{D}=0.1$ 


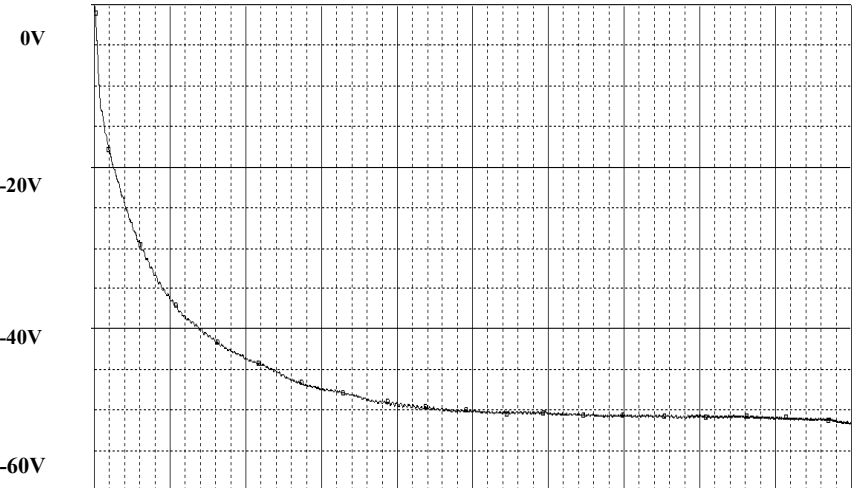

$\begin{array}{llllllllll}0 \mathrm{~ms} & 10 \mathrm{~ms} & 20 \mathrm{~ms} & 30 \mathrm{~ms} & 40 \mathrm{~ms} & 50 \mathrm{~ms} & 60 \mathrm{~ms} & 70 \mathrm{~ms} & 80 \mathrm{~ms} & 90 \mathrm{~ms}\end{array}$ V (L2:2,V1:-)

Fig 11. Duty cycle Vs output voltage when $\mathrm{D}=0.2$

oV

$-50 v$

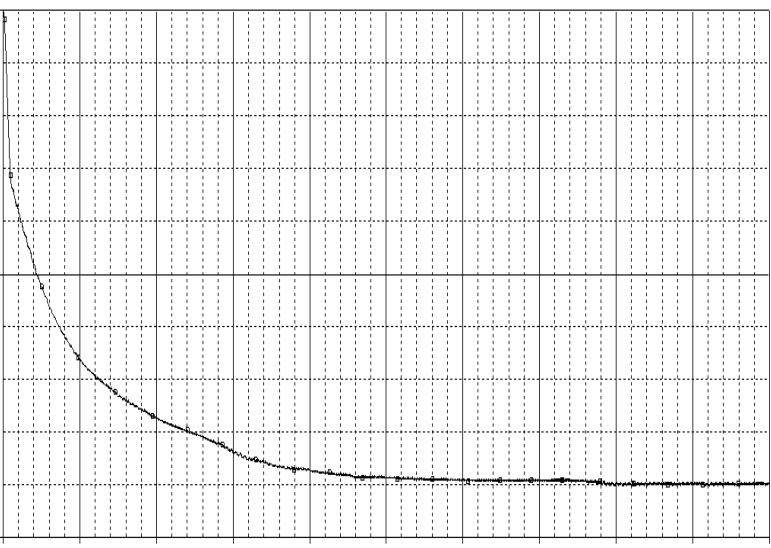

$\begin{array}{llllllllll}0 \mathrm{~ms} & 10 \mathrm{~ms} & 20 \mathrm{~ms} & 30 \mathrm{~ms} & 40 \mathrm{~ms} & 50 \mathrm{~ms} & 60 \mathrm{~ms} & 70 \mathrm{~ms} & 80 \mathrm{~ms} & 90 \mathrm{~ms}\end{array}$ V (L2:2,V1:-) Time

Fig 12. Duty cycle Vs output voltage when $\mathrm{D}=0.4$

$0 \mathrm{v}$

$-50 \mathrm{~V}$

$100 \mathrm{~V}$

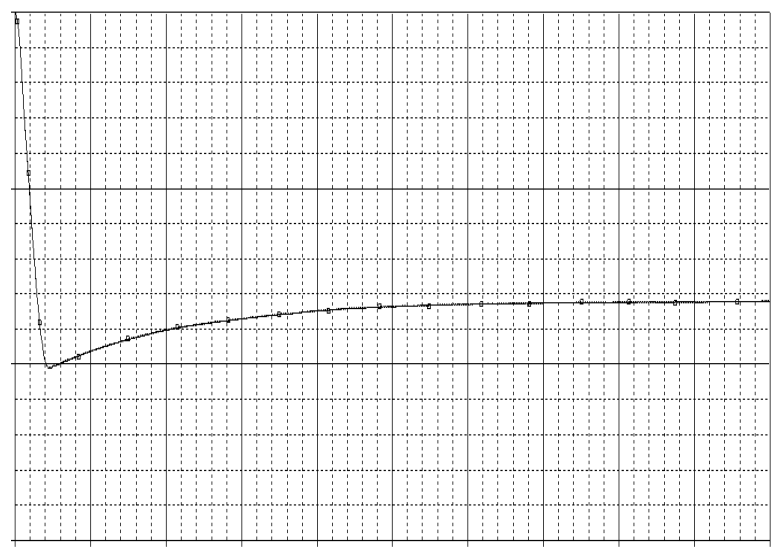

$\begin{array}{llllllllll}0 \mathrm{~ms} & 10 \mathrm{~ms} & 20 \mathrm{~ms} & 30 \mathrm{~ms} & 40 \mathrm{~ms} & 50 \mathrm{~ms} & 60 \mathrm{~ms} & 70 \mathrm{~ms} & 80 \mathrm{~ms} & 90 \mathrm{~ms}\end{array}$

V (L2:2,V1:-) Time

Fig 13. Duty cycle Vs output voltage when $\mathrm{D}=0.7$

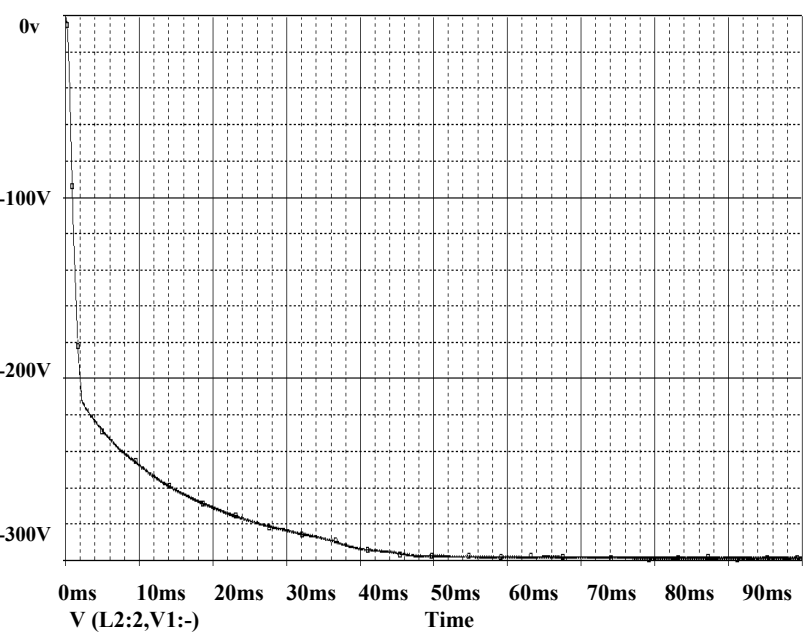

Fig 14. Duty cycle Vs output voltage when $D=0.8$

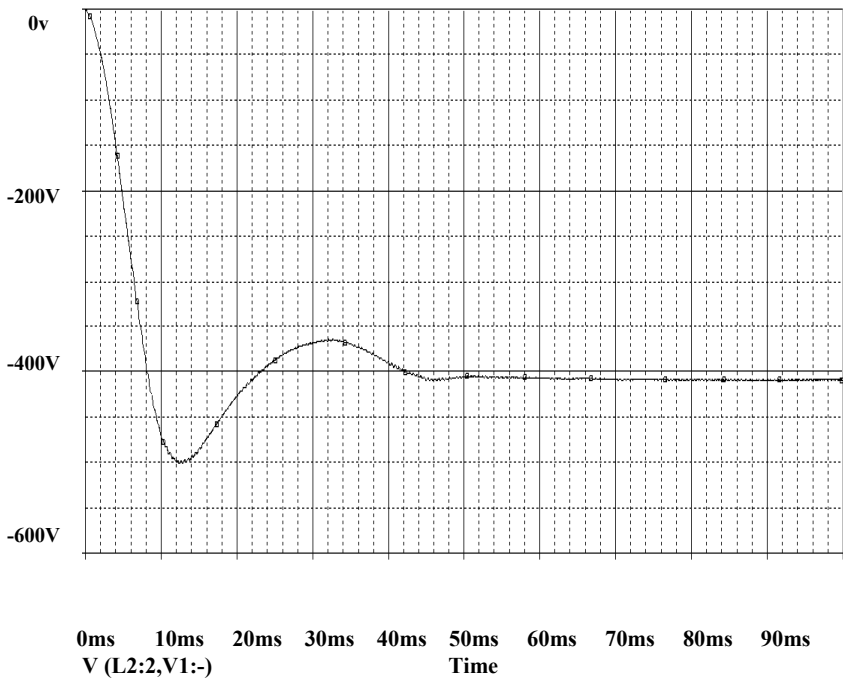

Fig 15 . Duty cycle Vs output voltage when $\mathrm{D}=0.9$

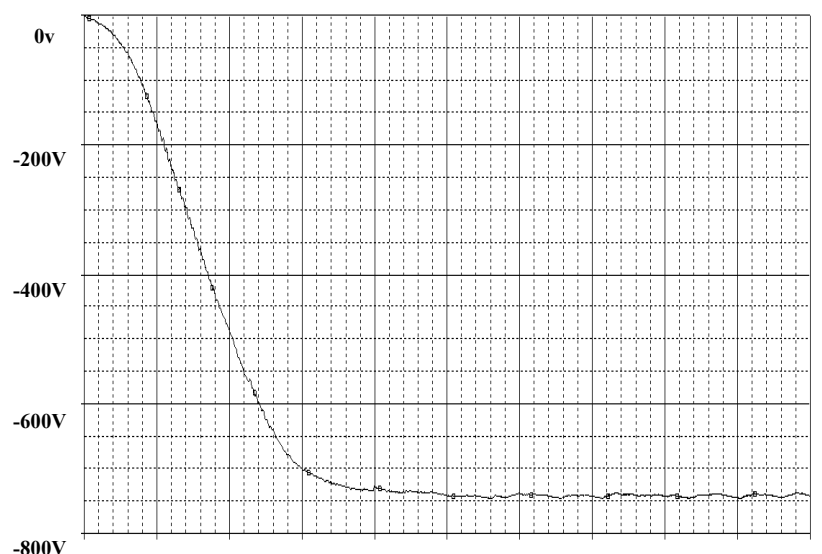

$\begin{array}{llllllllll}0 \mathrm{~ms} & 10 \mathrm{~ms} & 20 \mathrm{~ms} & 30 \mathrm{~ms} & 40 \mathrm{~ms} & 50 \mathrm{~ms} & 60 \mathrm{~ms} & 70 \mathrm{~ms} & 80 \mathrm{~ms} & 90 \mathrm{~ms}\end{array}$ V (L2:2,V1:-) Time

Fig 16. Duty cycle Vs output voltage when $\mathrm{D}=0.95$ 


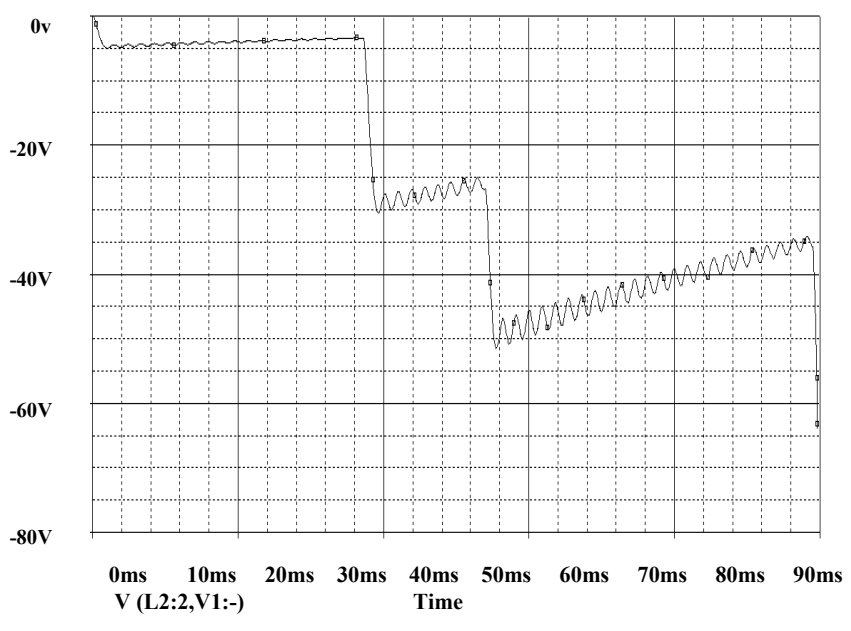

Fig 17: : Duty cycle Vs output voltage when $\mathrm{D}=0.99$

\section{COMPARISON WITH AC TRANSFORMER}

In figure 18, the basic blocks of the newly designed DC transformer, where the middle block performs the conversion of the DC voltage as it is obtainable in case of the AC circuit (Fig: 19). In fig: 18, which is the blocks of a DC transformer, takes DC voltage as the input and it goes to the electronic converter. PWM control is applied to the electronic converter to convert the DC voltage either step up or step down according to the duty cycle used. The energy transfer from the input to the output is capacitive. Whereas, AC transformer takes $\mathrm{AC}$ voltage as input. The input is applied to the winding where energy transfer is taken place inductively to a step up or step down voltage according to the winding ratio.

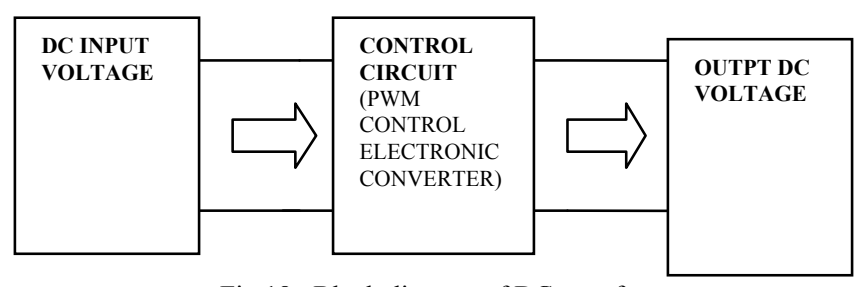

Fig 18 : Block diagram of DC transformer

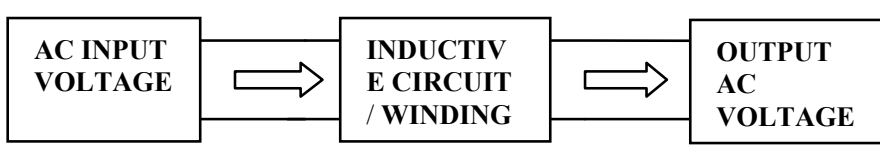

Fig 19 : Block diagram of AC transformer

\section{A. Limitations}

a. The Cuk converter uses high number of reactive components and high current stresses on the diode and the capacitor take place.

b. During simulation, the switch, diode and passive components are assumed ideal, i.e. linear in nature. But the nonlinearities or parasitic of practical devices and components may, however, greatly affect some performance parameters of DC-DC converters. This effect causes the efficiency of the circuit to decrease. However, with careful design the efficiency of the circuit can be kept above $90 \%$. c) Hard switching in a power circuit causes power losses. During turn-on and turn-off process, the power device has to withstand high voltage and current simultaneously, which results in high switching losses and stress. To avoid this problem, proposed DC transformer is used by which ZVS (Zero Voltage Switching) and ZCS (Zero Voltage Switching) is achieved.

\section{REFERENCES}

[1] Rashid M. H., “Power Electronics Handbook,” Academic Press, An Imprint of Elsevier, San Diago, California, Chapter 13 and 15, 2004.

[2] Slobodan Ćuk, "Switching DC-to-DC Converter with Zero Input or Output Current Ripple," IEEE Industry Applications Society Annual Meeting, 1978 Record, Toronto, ONT, USA, pp 1131-1146, October $1-5,1978$

[3] Rashid M. H., "Power Electronics Circuits, Device, and Applications," Prentice Hall of India Private Limited, Third Edition, pp 166-221, 2004.

[4] Slobodan Ćuk, "A New Zero Ripple Switching DC-to-DC Converter," IEEE Power Electronics Specialist Conference Record, Atlanta, CA, USA, pp 12-32, 1980.

[5] Rashid M H.. and Rashid H. M. "SPICE FOR POWER ELECTRONICS AND ELECTRIC POWER", $2^{\text {nd }}$ Edition, Taylor \& Francis Group, New work.

[6] Middlebrook R. D., and Slobodan Ćuk, "Modeling and Analysis Methods for DC to-DC Switching converters," IEEE International Semiconductor Power Converter Conference Record, , Lake Buena Vista, FL, USA, pp 90-111, 1977.

[7] Ned Mohan, Undeland Tore M., and Willium P. Robbins, "Power Electronics- Converters, Applications, and Design, "John Wiley and Sons Inc., Second Edition, pp 161-195, and 669-695, 1995.

[8] Veffer H., "High current, Low inductance GTO and IGBT Snubber Capacitors," Siemens Components, pp 81-85, June 1990.

[9] Slobodan Ćuk, "Basics of Switched Mode Power Conversion: Topologies, Magnetics and Control.” .

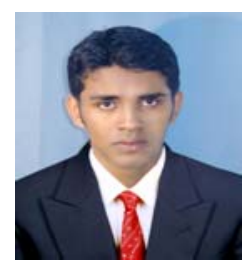

Md. Rakibul Hasan is working as an Engineer in Atomic Energy Research Establishment, Bangladesh Atomic Energy commission at Ganakbari, Savar, Dhaka Bangladesh. Currently he is working with Microcontroller. His research activities are related to DC to DC Converter, Power Electronics, Renewable Energy (Solar), DSP. Engineer Rakib is graduated from Military Institute of Science and Technology, Dhaka, Bangladesh. He is a co-author of an international journal paper, "Developing a Neural network based method for faster face recognition by training and simulation", International Journal of Engineering Science and Technology (IJEST) ISSN: 0975-5472 (online version), Vol. 2, Issue No. 11, page 6694-6703, 2010.

E-mail: rakib_eece@yahoo.com

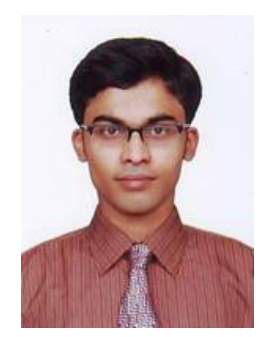

Mohammad Ashraf Hossain Sadi was born in Comilla, Bangladesh in 1987.He received his B.Sc. in Electrical and Electronic Engineering from Rajshahi University of Engineering \& Technology, Bangladesh in May 2009. He has been working as a Lecturer at the Department of Electrical and Electronic Engineering of Stamford University Bangladesh, since 2009. He is a member of IACSIT. His conducted courses in the undergraduate level are Optoelectronics, Power System, Electronics and Microwave Engineering etc. His research interests include Nanotechnology/Photonics, Renewable Energy, Power System and Power Electronics. He has around 5 (International 3, National 2) published journal \& 2 international conference paper in distinguished journals \& conferences 
in the field of Photonics, Nanotechnology, Power Electronics \& Image Processing.

E-mail: ashraf.sadi@gmail.com

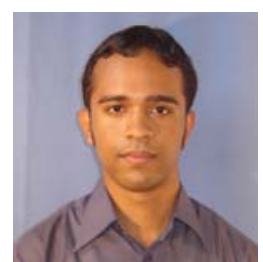

Ifat-Al-Baqee is a Lecturer at Department of Electrical and Electronic Engineering of Stamford University Bangladesh at Siddeswari, Dhaka, Bangladesh. He teaches electromagnetism and electronics. His research activities are related to Image Processing and Biomedical Engineering. Lecturer Baqee is graduated from Military Institute of Science and Technology, Dhaka, Bangladesh $\mathrm{He}$ is a co-author of an international journal paper, "A Proposed Design for the Development of Vital Sign (Electrocardiogram) Patient Monitoring System", International Journal of Engineering Science and Technology (IJEST) ISSN: 0975-5472 (online version), Vol. 2, Issue No. 10, page 5813-5817, 2010..

E-mail: ifat_eee@stamforduniversity.edu.bd

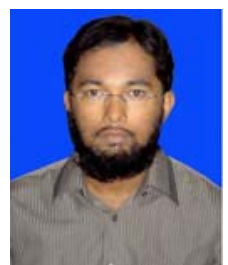

Md. Shahidul Islam Bhuiyan is working as an Engineer in Atomic Energy Research Establishment, Bangladesh Atomic Energy commission at Ganakbari, Savar, Dhaka Bangladesh. Currently he is working with Microcontroller, Renewable energy (Solar).His research activities are related to analysis share stress between Aluminum, Brass and copper. Engineer Shahid is graduated from Chittagong University of Engineering \&Technology, Chittagong, Bangladesh.

E-mail: sohe195@gmail.com

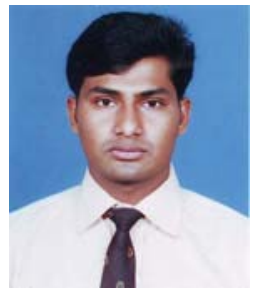

Md. Kamal Hossain was born in Rangpur, Bangladesh. He received his B.Sc. in Electrical and Electronic Engineering from Rajshahi University of Engineering \& Technology, Bangladesh in May 2009. He has been working as a Lecturer at the Department of Electrical and Electronic Engineering of Stamford University Bangladesh, since 2009.He is doing his M.Sc. in Bangladesh University of Engineering \& Technology. His conducted courses in the undergraduate level are Power Electronics, Power System, Microwave Engineering etc. His research interests include Renewable Energy and Power Electronics. He has around 4 (International 2 National 2) published journal paper in distinguished journals in the field of Electromagnetics, Power Electronics \& Power System.

E-mail:kamal04_eee@yahoo.com 